FERMILAB-Conf-93/222

\title{
Thermal Information Regarding the Cooldown and Operation of Liquid Argon Calorimeters
}

\author{
R.A. Rucinski, W.E. Cooper, K.D. Dixon, K.J. Krempetz, G.T. Mulholland, \\ K. Primdahl and J.B. Urbin \\ Fermi National Accelerator Laboratory \\ P.O. Box 500, Batavia, Illinois 60510
}

July 1993

Presented at the Cryogenic Engineering Conference, Alberquerque, New Mexico, July 12-16, 1993 


\section{Disclaimer}

This report was prepared as an account of work sponsored by an agency of the United States Government. Neither the United States Government nor any agency thereof, nor any of their employees, makes any warranty, express or implied, or assumes any legal liability or responsibility for the accuracy, completeness, or usefulness of any information, apparatus, product, or process disclosed, or represents that its use would not infringe privately owned rights. Reference herein to any specific commercial product, process, or service by trade name, trademark, manufacturer, or otherwise, does not necessarily constitute or imply its endorsement, recommendation, or favoring by the United States Government or any agency thereof. The views and opinions of authors expressed herein do not necessarily state or reflect those of the United States Government or any agency thereof. 


\title{
THERMAL INFORMATION REGARDING THE COOLDOWN AND OPERATION OF LIQUID ARGON CALORIMETERS*
}

\author{
R. A. Rucinski, W. E. Cooper, K. D. Dixon, \\ K. J. Krempetz, G. T. Mulholland, K. Primdahl, J. B. Urbin \\ Fermi National Accelerator Laboratory \\ P. O. Box 500 \\ Batavia, IL 60510
}

\begin{abstract}
Three liquid argon calorimeters were cooled down and operated as part of the D-Zero detector at Fermi National Accelerator laboratory. The largest vessel contains 248 metric tons of uranium and copper plates and $19 \mathrm{~kL}$ (5000 gal.) of liquid argon. The other two vessels are mirror images, each containing 185 metric tons of uranium and stainless steel plates and $12.1 \mathrm{~kL}$ (3200 gal.) of liquid argon. The cool down was accomplished by convection heat transfer between boiling liquid nitrogen filled finned heat exchangers and argon gas inside the vessels. Information regarding the general internal geometry of the calorimeters, cool down, operation, and steady state heat loads will be presented.
\end{abstract}

\section{Introduction}

The D-Zero particle detector has three liquid argon calorimeters in line along the particle accelerator's beamline. Protons and anti-protons are accelerated in opposite directions and then collided at an interaction point. The particle accelerator's beamline passes through the center of each vessel with the proton anti-proton interaction point located in the middle of the central calorimeter (CC). The energy release from the collision is measured within the three calorimeters. Each calorimeter is a vacuum jacketed liquid argon vessel that has been cut open, packed with high energy particle detectors, and welded back up. The particle detectors are kept submerged in liquid argon during operation. A background document containing design details of the argon calorimeter has been previously written. ${ }^{1}$

The shape of the calorimeters was chosen to maximize hermeticity, that is, to maximize the likelihood that particles originating at the interaction region would pass through the active detector. Figure 1 shows a half section of the detector. The CC has a torus shape. A hole in the middle was left for central tracking detectors. The north end calorimeter and south end calorimeter are mirror images of each other. The concave/convex head arrangement minimizes the space between the CC and end calorimeter's (EC's).

\footnotetext{
* Work Supported by the U.S. Department of Energy under contract No. DE-AC02-76CH03000
} 


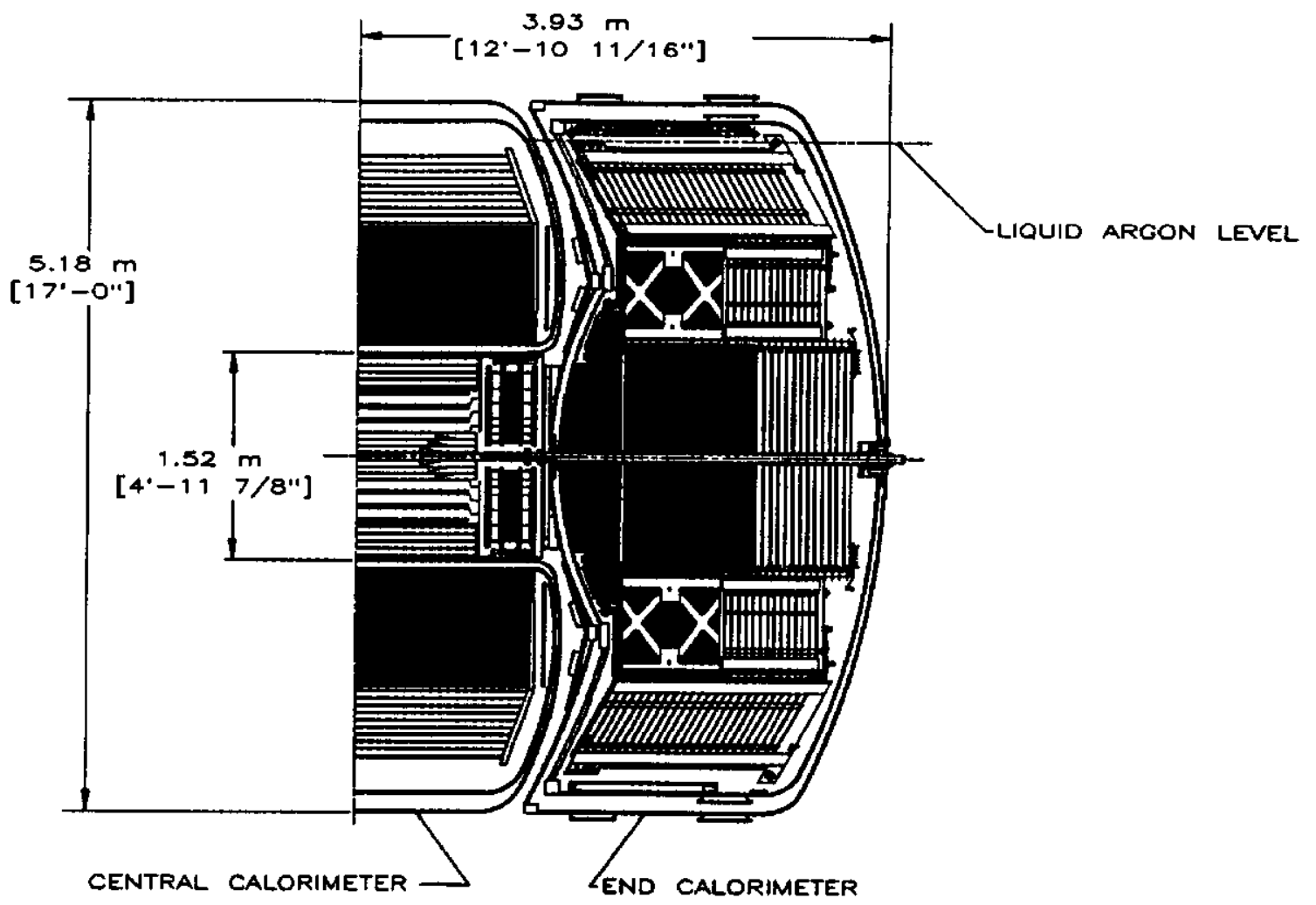

Figure 1. D-Zero Argon Calorimeter vessels shown loaded with particle detectors. Only one half of the detectors are shown; Vessels and modules are symmetric about vertical centerline.

The geometry and the large thermal mass of the particle detectors are unusual. The particle detectors are constructed of uranium, copper, and stainless steel plates. The modules are constructed as a repetitive plate, space, signal board, space, plate series. A typical signal board is $1.2 \mathrm{~mm}$ thick and made of G-10. All the argon filled spaces between the signal boards and plates are $2.29 \mathrm{~mm}$. The detectors were made in trapezoidal shaped pieces called modules. Sixteen or thirty-two of these modules were then stacked to form full rings inside the vessels. The modules for the $\mathrm{CC}$ were built with plates being horizontal, that is, the length of the plates are parallel to the beamline. A thin stainless skin with small holes encased each module. Due to the geometry of the modules in the $\mathrm{CC}$, the dominant mode of heat transfer in the module cool down was expected to be conduction. The modules for the EC's were built mostly with vertical plates, perpendicular to the beamline. The exception is that the outermost module plates were built 30 degrees from the vertical. Although this geometry in the EC appeared to lend itself to free convection heat transfer along the plate surfaces, it is thought that conduction heat transfer through the modules was more dominant during cool down.

A sectional view of the module loaded calorimeters is shown in figure 1 . The darker colored plates nearer the interaction point are made of uranium. The uranium plate thicknesses are either 3,4 , or $6 \mathrm{~mm}$ depending on the module type. The thicker outlined plates in the CC are copper plates $46.5 \mathrm{~mm}$ thick. The thicker outlined plates in the EC are also $46.5 \mathrm{~mm}$ thick but are made of 304 stainless steel. The very thick back plate on the outermost module in the EC is $110 \mathrm{~mm}$ thick 304 stainless steel. Table 1 lists the approximate weight and thermal mass of the $C C$ and $E C$ vessel contents. 
Table 1. Detector weights, thermal masses

\begin{tabular}{lccccc} 
& $\begin{array}{c}\text { Weight } \\
\text { (metric tons) }\end{array}$ & $\begin{array}{c}\text { Thermal Mass } \\
\text { (Mjoules) }\end{array}$ & \multicolumn{2}{c}{$\begin{array}{c}\text { North or South EC } \\
\text { (meight }\end{array}$} & $\begin{array}{c}\text { Thermal Mass } \\
\text { (Mioules) }\end{array}$ \\
Copper & 106.70 & 7292 & 0.0 & 0. \\
G-10 & 4.06 & 468 & 3.10 & 358 \\
Uranium & 141.47 & 3056 & 50.41 & 1089 \\
304 Stainless Steel & 18.78 & 1453 & 134.89 & 10436 \\
Cryostat, Stainless Steel & 10.32 & 799 & 12.88 & 997 \\
Total & 281.33 & 13068 & 201.28 & 12880
\end{tabular}

The cooling requirement of the three cryostats is provided by an inventory maintained $76.6 \mathrm{~kL}$ liquid nitrogen storage dewar. The liquid nitrogen is pressure fed from the storage dewar. A phase separator and subcooler upstream of the cryostats provide low quality liquid to the control valves of the cryostat cooling loop inlet. Each cryostat is equipped with two sets of cooling loops (see figure 2). The operating loop is in the gas space. The cool down loop straddles the apex of the calorimeter and is located below the operating liquid argon level. The cooling loops are constructed of $19 \mathrm{~mm} \mathrm{OD.,}$ $1.65 \mathrm{~mm}$ wall type 304 stainless steel tubing with $0.5 \mathrm{~mm}$ thick, $9.53 \mathrm{~mm}$ high spiral wrapped brazed copper fins at a 12 fins per inch spacing. There is approximately $36.0 \mathrm{~m}$ of finned tubing for an EC operating loop and $71.5 \mathrm{~m}$ total for the EC cool down loop. The CC has $37.7 \mathrm{~m}$ of finned tubing for its operating loop and $139.2 \mathrm{~m}$ total for the cool down loop. The liquid nitrogen inlet ( $4 \mathrm{~m}$ of $11 / 2^{\prime \prime} \mathrm{sch}$. 40 pipe) and outlet piping ( $4 \mathrm{~m}$ of 2 " sch. 40 pipe) inside the vessel on each end of the finned tubing adds additional surface area. The operating loops of all the cryostats were sized to have about $10 \mathrm{~kW}$ of argon condensing power. The cool down loop of the $\mathrm{CC}$ was sized at $40 \mathrm{~kW}$ condensing capacity. The narrower EC cryostats could only fit a nominal $20 \mathrm{~kW}$ cool down loop in the available space. The cool down loops were intended to only operate during cool down. The control valve arrangement (shown in figure 3 ) allows flexibility to change the loop operating temperature as well as to maintain a steady pressure in the cryostat.

A $76.6 \mathrm{~kL}$ liquid argon storage dewar also is part of the cryogenic system at D-Zero. This storage dewar is housed below ground and is cooled by means of a liquid nitrogen

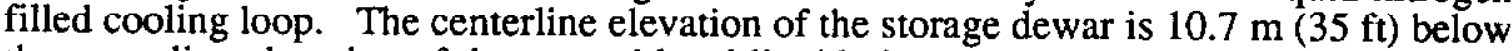
the centerline elevation of the ground level liquid nitrogen storage dewar and $2.9 \mathrm{~m}(9.4$ $\mathrm{ft}$ ) below the calorimeter centerline. This storage dewar received the initial liquid argon deliveries from vendor supplied over the road tankers. Transfer lines with appropriate control valves connect the argon storage dewar to each cryostat. Liquid or gas transfers in both directions are possible.

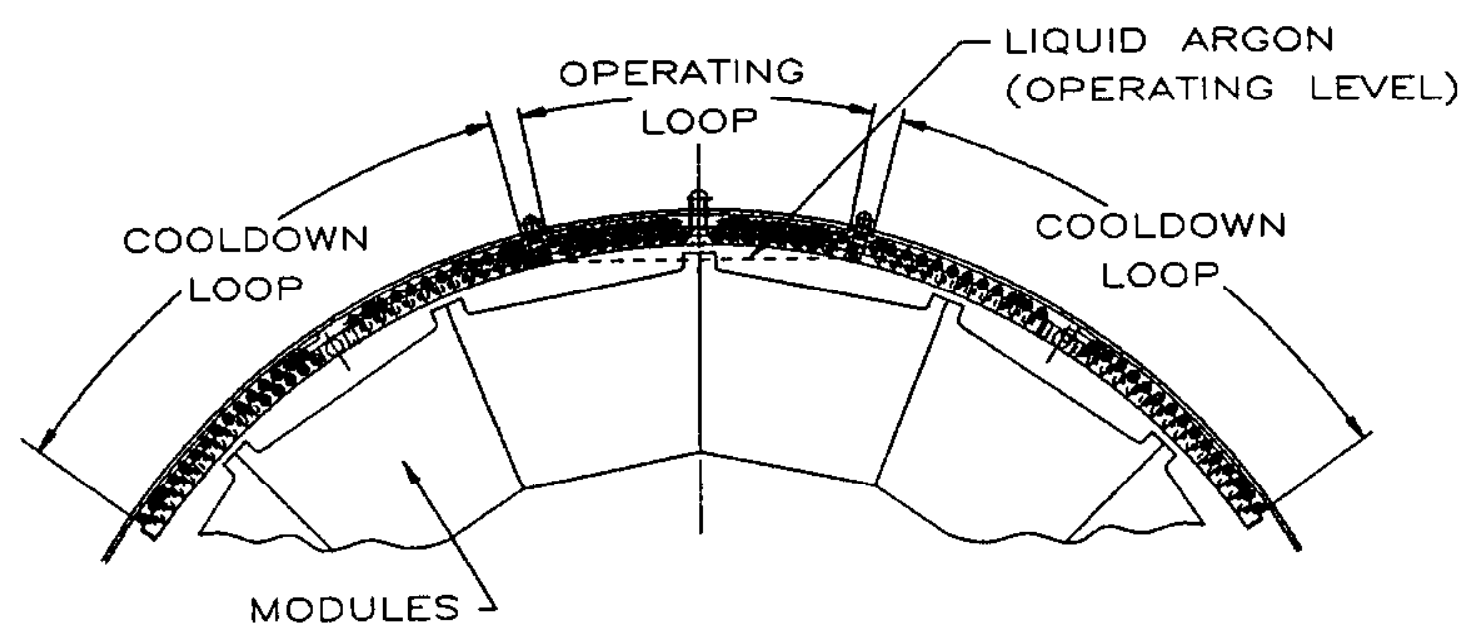

Figure 2. Vessel cooling loops. Note small gas space 


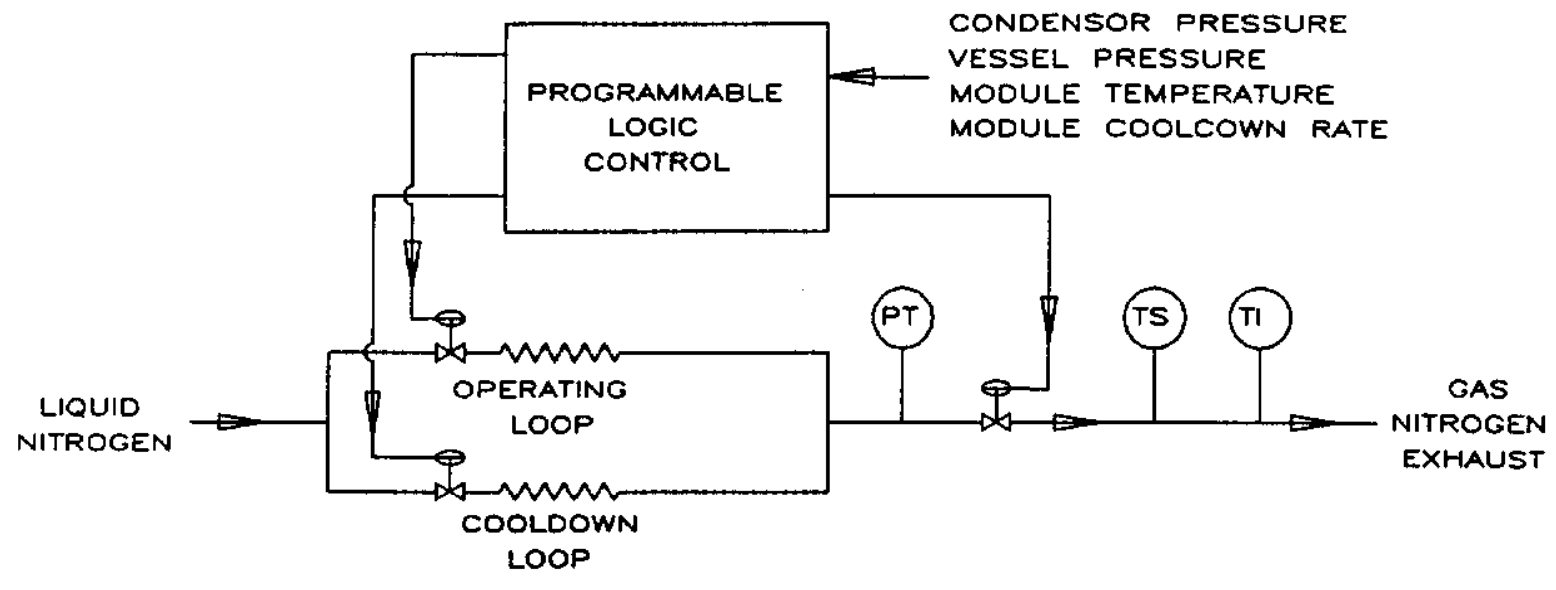

Figure 3. Control valve configuration for the operating and cool down loops.

\section{Calorimeter Cool down}

The liquid argon calorimeters were cooled and filled sequentially: first the central calorimeter (CC) and then the end calorimeters (EC's). The central calorimeter was cooled approximately a year before the end calorimeters. The initial central calorimeter cool down took place while the calorimeter was in the D-Zero assembly hall. After initial tests of the CC were completed using cosmic rays, the calorimeter was emptied. Cooling was stopped for three months while construction on other parts of the detector took place. A temporary gas argon jumper tied the CC to the liquid argon storage dewar while its modules warmed to an average temperature of $140 \mathrm{~K}$. The cooling loop in the liquid argon storage dewar was used to control the pressure in the CC. It was desirable not to pop the main relief valve on the calorimeter and risk contaminating the liquid argon with air. The $\mathrm{CC}$ modules were re-cooled and the vessel was re-filled with liquid argon over a period of about 5 days.

The initial CC cool down took approximately 9 days. The cool down rate was limited by constraints on temperature differences within individual modules, between modules, between adjacent modules, between modules and their supports, and between the module supports and the inner cryostat vessel walls. Temperatures were measured with RTD's. The permitted temperature differences are given in Table 2 and were chosen to limit thermal stresses in the modules, support structure, and the calorimeter vessel. The cool down time is defined to end when the average module temperatures were $100 \mathrm{~K}$ and the vessels could be filled with liquid while maintaining temperature difference constraints.

Table 2. Temperature constraints for the central calorimeter: maximum permitted temperature differences

Any 2 measurement points within a single $\mathrm{CC}$ module:

Coarse hadronic $(\mathrm{CH})$ modules:

Fine hadronic ( $\mathrm{FH})$ modules:

$100 \mathrm{~K}$

Electromagnetic (EM) modules:

$100 \mathrm{~K}$

Any 2 module endplates:

$50 \mathrm{~K}$

Any 2 module endplates:

$100 \mathrm{~K}$

The endplates of any 2 adjacent modules:

$100 \mathrm{~K}$

$\mathrm{CH}$ module structural "skins" and he

$\mathrm{CH}$ module support beam and the cryostat inner vessel wall (closest sensors):

$25 \mathrm{~K}$

$20 \mathrm{~K}$ 
The north EC took approximately 14 days for cool down. The south EC took 16 days for it's initial cool down. Temperature constraints imposed for the cool down are given in Table 3 . The EC's cooling loops have $60 \%$ less capacity than the CC vessel which resulted in a longer cool down for the EC's relative to the CC.

Table 3. Temperature constraints for the end calorimeters: maximum permitted temperature differences

Any 2 measurement points within a single EC module:

Outer hadronic $(\mathrm{OH})$ modules:

Middle hadronic $\mathrm{MH}$ ) modules

Inner hadronic (IH) module

Electromagnetic module

Any 2 adjacent module endplates:

$\mathrm{OH}$ modules:

MH modules:

no constraint

$100 \mathrm{~K}$

no constraint

$50 \mathrm{~K}$

Any 2 adjacent endplates of $\mathrm{MH}$ and $\mathrm{OH}$ modules through which

the $\mathrm{MH}$ moudle ring is supported:

IH module endplate to MH support module endplate:

$40 \mathrm{~K}$

$20 \mathrm{~K}$

IH module central structural tube to IH module structural tie plates:

$\mathrm{OH}$ support modules to nearest sensors on the $\mathrm{OH}$ support structure:

$20 \mathrm{~K}$

$20 \mathrm{~K}$

$40 \mathrm{~K}$

$25 \mathrm{~K}$

The initial cool down rates of both the central calorimeter and the end calorimeters were approximately .4 to $1.2 \mathrm{~K} / \mathrm{hr}$. A graph of one module temperature sensor versus time for the CC cool down is shown in figure 4. Towards the end of the cool down, (especially in the EC's) the capacity of the cooling coils limited the cool down rate. This was evident by the numerous times liquid nitrogen was sensed in the vent line from the cooling loops. Whenever liquid was sensed we had to reduce the liquid nitrogen flow rate for both economical and safety reasons. The safety reason was due to the vent line also serving as the outlet piping of the argon calorimeter safety relief valves.

Cool down rates for the EC's were indirectly limited at times by unequal flow through cool down coils that were connected in parallel. Flow imbalances through the cooling coils typically resulted in left to right temperature differences that warranted slowing of the cool down. An additional imposed criterion for the south EC was contact of a module to parts of the vessel. This also halted cooling for periods of time.

The cooling loops were operated at $0.41 \mathrm{MPa}$ (60 psia) during the cool down causing the loops to run warmer than the condensing temperature of the $0.14 \mathrm{MPa}(20 \mathrm{psia})$ argon gas inside the vessel. This prevented liquid argon from raining on the top of the modules which could cause unacceptable temperature gradients. In steady state mode the condenser pressure is lowered from $0.41 \mathrm{MPa}(60 \mathrm{psia})$ to $0.17 \mathrm{MPa}(25 \mathrm{psia})$ to increase the temperature difference between the cooling coil and argon gas in the calorimeters.

\section{Argon Filling}

Due to the relative elevations and allowable working pressures of the storage dewar and calorimeters, the argon filling process takes place in two stages. The first stage is a pressurized liquid transfer from the liquid argon storage dewar into the bottom of the cryostat. The second stage is a condensing phase that takes gas from the liquid argon storage dewar and condenses it on the calorimeter cooling loops. The time duration spent on each portion of the fill process depends on the available liquid head in the storage dewar. The filling operation begins only after it is ensured that the module average temperature is less than $100 \mathrm{~K}$ and the temperature constraints listed in tables 2 and 3 can be held. 


\section{Temperature (K)}

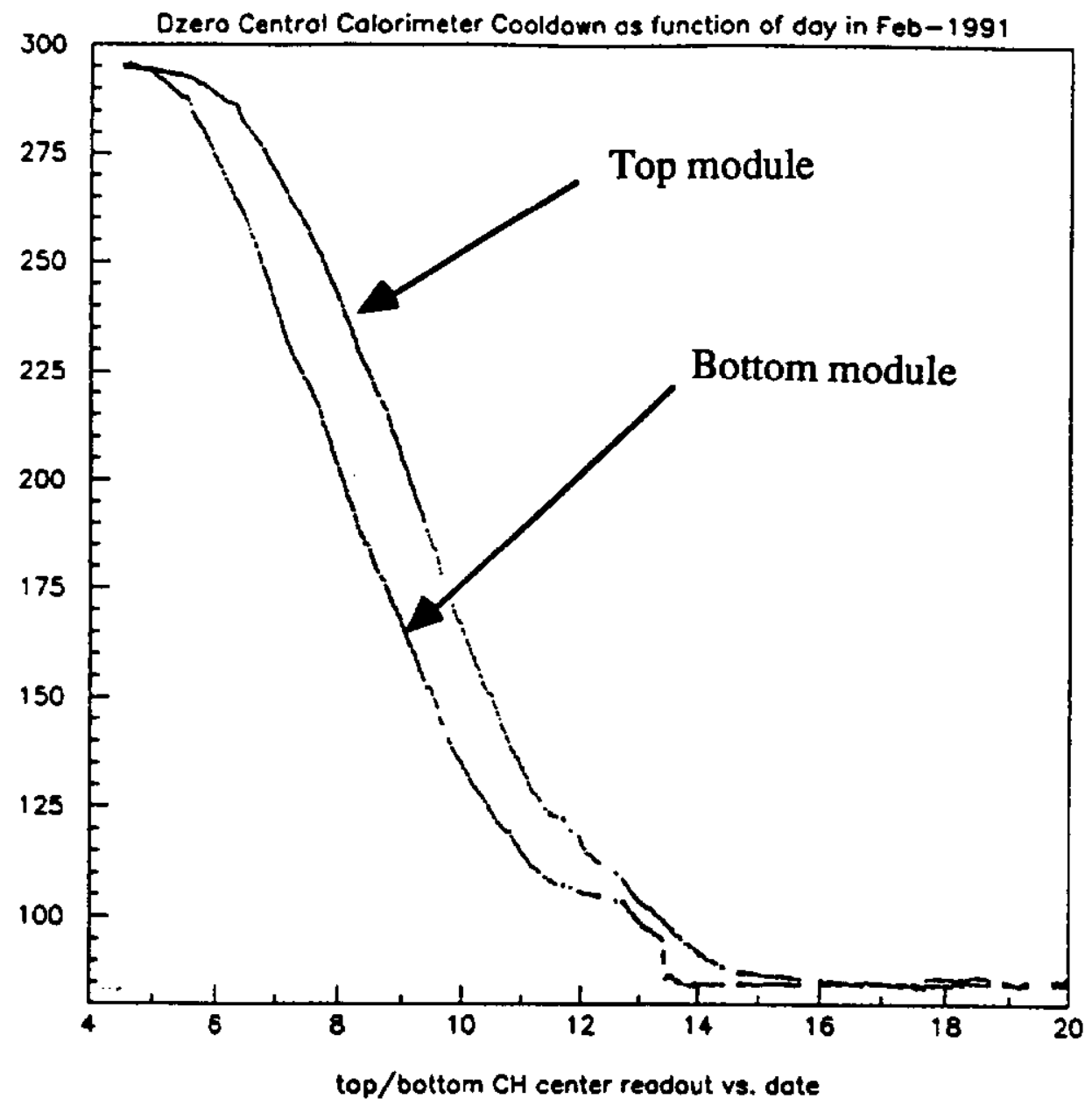

Figure 4. Temperature of a module during the initial $\mathrm{CC}$ cool down.

Only one cryostat is filled at a time. After the cold (empty) detector was moved to the collision hall, all three cryostats were filled in succession. It took 91 hours to completely fill all three cryostats. Of that time 36 hours was spent for the liquid transfer portion and 55 hours for the condensing portion to complete the fill. Approximately 250 to 300 gallons was transferred during the condensing portion of the fill.

\section{Operations}

After the three Calorimeters were cooled down and filled, the cryogenic system was operated for about one week. This was to test the cryogenic system and make sure no major problems existed before moving the calorimeters into the collision hall. Major repairs or modifications to the cryogenic system would be much harder in the collision hall because there is much less space and no overhead crane.

The cryogenic system performed well so after one week of operations the calorimeters were emptied. After the three calorimeters were emptied, they were disconnected from the cryogenic system by way of u-tubes. A temporary gas line from 
the three calorimeters to the liquid argon dewar was installed. It took about two weeks to move the detector from the assembly hall to the collision hall and reconnect the cryogenic system to the calorimeters. For the two weeks the calorimeters were not cooled, the average module temperature rose to about $125 \mathrm{~K}$.

Once the cryogenic system was hooked back up, the calorimeters were cooled back down to liquid argon temperatures. Within a few days the calorimeters were ready to be filled. During February 22-26, 1992 the calorimeters were filled again with liquid argon and have been in this state for over one year now.

Many calculations have been made on the total heat load of the cryogenic system. A summary of the steady state system heat load was calculated to be $4.1 \mathrm{~kW}$ for the calorimeters and $1.2 \mathrm{~kW}$ for the storage dewars. 1 Since operations began, the average LN2 consumption has been $167 \mathrm{l} / \mathrm{hr}(44 \mathrm{gals} / \mathrm{hr})$. This corresponds to approximately 7.4 $\mathrm{kW}$ assuming that all the refrigeration comes from the heat of vaporization. The exit temperature from the heat exchanger in the calorimeters is around $100 \mathrm{~K}$ so this assumption has some validity. The argon and liquid nitrogen storage dewar consumption was measured to be $48.11 / \mathrm{hr}(12.7 \mathrm{gal} / \mathrm{hr})$ or $2.1 \mathrm{~kW}$ of refrigeration. Arithmetic says that the three calorimeters use approximately $5.3 \mathrm{~kW}$ during steady state operation.

The pressure in all three calorimeters has been controlled at $137.894 \mathrm{KPa}+/-0.7 \mathrm{KPa}$ $(+/-20.0 \mathrm{psia}+/-0.1 \mathrm{psi})$. The pressure in the central calorimeter has been more stable than that in the end calorimeters: $+/-0.14 \mathrm{KPa}(0.02 \mathrm{psi})$ versus $+/-0.7 \mathrm{KPa}(+/-0.1 \mathrm{psi})$. The difference in pressure stability can be attributed to the difference in ullage volumes and control valves. The $\mathrm{CC}$ has the largest ullage volume of $0.87 \%$ of total volume while the EC ullage volume is only $0.56 \%$ of total volume. Also, the $\mathrm{CC}$ has a smaller operating loop inlet and outlet valve $\left(\mathrm{C}_{\mathrm{V}}=0.32\right.$ and 6.0$)$ versus the $\mathrm{EC}^{\prime} \mathrm{s}\left(\mathrm{C}_{\mathrm{V}}=0.80\right.$ and 14.0).

The temperature of each of the three calorimeters has remained fairly constant but reflects variations in the vessel pressure. Each calorimeter has three temperature measuring devices, vapor bulb thermometers, at the top, middle and bottom of the vessels. The middle temperature device in the central calorimeter has failed (the vapor bulb leaks) so no measurement is given for the middle Central Calorimeter temperature. There are also platinum resistor type temperature devices located near the vapor bulb thermometers, but these devices are two wire devices and were not intended to be very accurate. The platinum resistor temperature devices were installed to confirm the vapor bulb thermometers were working properly. The temperature stability of the three calorimeters is shown in table 5.

Table 5. Temperature stability of the calorimeters

Central Calorimeter

North End Cap Calorimeter

South End Cap Calorimeter

$\begin{array}{ccc}\text { Bottom } & \text { Middle } & \text { Top } \\ +/-.03 \mathrm{~K} & * * * * & +/-.04 \mathrm{~K} \\ +/-.10 \mathrm{~K} & +/-.08 \mathrm{~K} & +/-.16 \mathrm{~K} \\ +/-.28 \mathrm{~K} & +/-.29 \mathrm{~K} & +/-.42 \mathrm{~K}\end{array}$

The temperature uniformity varies from calorimeter to calorimeter. All three calorimeters are warmer at the top. This is expected because the majority of the heat loss is near the signal nozzle ports at the top. The middle and bottom temperature sensors indicate approximately the same temperature. The central calorimeter and north end calorimeter have a very uniform temperature throughout the vessel, with a $.4 \mathrm{~K}$ rise near the top. The south end calorimeter is $2.3 \mathrm{~K}$ warmer at the top. These temperature gradients are confirmed by both the vapor bulbs and platinum resistor thermometers.

There have been three operational difficulties that have been or will be corrected. After the initial cool down and fill, ice formation on the signal port feedthroughs was evident. This was undesirable because many electrical connectors were in the area. Also a concern arose about the $\mathrm{O}$-rings that sealed the port penetration. This problem was corrected by installing small strip heaters around each signal port that apply an about 500 
watts to each calorimeter. As mentioned earlier, the middle vapor bulb thermometer on the central calorimeter needs to be repaired. Also, the large temperature difference between the top and middle or bottom of south end calorimeter needs to be understood and if possible, eliminated. A uniform argon density (and hence, a uniform argon temperature) is important in obtaining reliable physics data from the calorimeters. Tests are planned this summer to try to understand and solve this problem.

\section{Summary}

The three liquid argon calorimeters that are part of the D-Zero detector contain modules that are constructed of uranium, copper, and stainless steel plates. The content of each calorimeter has a thermal mass of 13,000 MJoules when cooled down to liquid argon temperature. The cool down of the cryostats were performed in 9 to 16 days depending on the cryostat and it's cooling loop size. The cooling loops in the cryostats were liquid nitrogen filled heat exchangers in a gaseous argon filled vessel. Once cold, all three calorimeters can be filled with approximately $43.2 \mathrm{Kl}$ of liquid argon in four days. The observed heat loads are slightly higher than the initial design calculations, but are acceptable. The cryogenic system has run reliably and within required physics parameters.

\section{References}

1. G. T. Mulholland et al., Cryogenic Design of the D-Zero Liquid Argon Collider Calorimeter, $A d v$. in Cryo., 33:1121 (1987). 